\title{
A quantum chemical computation insight into the donor-acceptor bond interaction of silver complexes with tetrylene
}

\author{
Tran Duc Sy ${ }^{1,5}$, Huynh Thi Phuong Loan ${ }^{2}$, Dang Tan Hiep, \\ Pham Van Tat ${ }^{4}$, Duong Tuan Quang ${ }^{5}$, Nguyen Thi Ai Nhung ${ }^{2 *}$ \\ ${ }^{1}$ Department of Chemistry, Quang Binh University \\ ${ }^{2}$ Department of Chemistry, Hue University of Sciences, Hue University \\ ${ }^{3}$ HCMC University of Food Industry, \\ ${ }^{4}$ Faculty of Science and Technology, Hoa Sen University \\ ${ }^{5}$ Department of Chemistry, Hue University of Education, Hue University
}

Received 11 February 2017; Accepted for publication 28 August 2017

\begin{abstract}
We computationally investigate the nature of chemical bonding from linear to bent structures of $\mathrm{N}$-heterocyclic carbene-analogues of silver complexes (called tetrylene) $\mathrm{AgCl}_{-\mathrm{NHE}_{\mathrm{Me}}}$ (Ag-NHE) with $\mathrm{E}=\mathrm{C}-\mathrm{Pb}$ using quantum chemical calculations at the BP86 level with the various basis sets def2-SVP, def2-TZVPP, and TZ2P+. The geometry calculations find that the equilibrium structures of Ag-NHE system show major differences in the bonded orientation of NHPb ligand in Ag-NHPb compared with NHE ligands the slighter homologues Ag-NHE $(\mathrm{E}=\mathrm{C}-\mathrm{Sn})$. The bond dissociation energy results show that the Ag-carbene bond in $\mathbf{A g - N H C}$ is a strong bond and decreases from the slighter to the heavier homologues. The EDA-NOCV results indicate that the ligand NHE in complexes is strong $\sigma$-donors and very weak $\pi$ donor. The NOCV pairs of the bonding show small $\pi$-back donation from the Ag to the $\mathrm{NHE}_{\mathrm{Me}}$ ligands.
\end{abstract}

Keywords. N-heterocyclic tetrylene, bond dissociation energy, quantum chemical calculations, bonding analysis.

\section{INTRODUCTION}

The first stable transition metal carbene complex was investigated in 1964 [1]; then the metal-ligand bonding in complexes of mixed carbene-halogen complexes (NHC-TMX with $\mathrm{TM}=\mathrm{Cu}, \mathrm{Ag}, \mathrm{Au}$ and $\mathrm{X}=\mathrm{F}-\mathrm{I}$ ) was published for using a charge decomposition analysis that was noticed for the first time by Frenking et al [2]. The chemical bonding between NHCs and group 11 metals has been investigated theoretically in the recent past [3]. Moreover, NHCs ligands can be stabilized by two nitrogen atoms and form stable complexes with transition metals ( $\mathrm{Ag}, \mathrm{Au})$ and with main-group elements [2]. The fact was that silver-NHCs complexes have been investigated in the recent past to behave as efficient catalysts in transesterification reactions [4]. Furthermore, silver-NHCs compounds are the most popular complexes used for NHCs transfer [5]. The development of NHCs complexes of silver has come about by the discovery of the transmetalation from silver-NHCs to other metal NHCs system. Unlike copper- and gold-NHCs systems, silver-NHCs can be synthesized without the need for anaerobic conditions [6] that has been shown in many biomedical applications within the last ten years. For example, in 2007 Youngs et al. [7] reviewed the synthesis, characterization, and applications of silver(I)-NHCs complexes for antibiotics applications. We especially pay attention to the use of metal-NHCs complexes as precursors for the synthesis of nanocrystals in which very few reports refer to syntheses and stabilization of metal nanocrystals through gold- and silver-NHCs complexes [8,9]. It has been known that the steric bulk of the NHC and the strength of the reducing agent were found to have an interesting influence on nanocrystals size, size contribution, and shape of the metal-NHCs adducts [10]. The formation of silver nanoparticles from the reduction of silver-NHCs complexes with the $\mathrm{C}_{n} \mathrm{H}_{2 \mathrm{n}+1}$ groups connected to nitrogen atoms in $\mathrm{NHC}$ ring that was also observed by $\mathrm{NaBH}_{4}$ in biphasic conditions $\left(\mathrm{CH}_{2} \mathrm{Cl}_{2} / \mathrm{H}_{2} \mathrm{O}\right)$ [11]. Recent reports suggested that the characterization and the bonding situation in transition metal complexes with NHCs ligands [12] and related 
systems [13] are not limited to carbon as a central atom, but that is can be extended to the heavier group 14 homologues that have been extensively investigated in the recent past $[2,14,15]$.

Our interest lies in having a thorough insight into the structures and bonding situation of silver- $\mathrm{NHC}_{\mathrm{Me}}$ and analogues $\left[\mathrm{AgCl}-\left\{\mathrm{NHE}_{\mathrm{Me}}\right\}\right]$ (Ag-NHE) complexes with $\mathrm{E}=\mathrm{C}-\mathrm{Pb}$. In this regard, we have recently reported and also have employed in a variety of a series of $\left[\mathrm{AuCl}-\left\{\mathrm{NHE}_{\mathrm{Me}}\right\}\right]$ complexes [15]. During the course of the investigation of the silver complexes that carry tetrylene we became interested in looking for the existence of silver(I)$\mathrm{NHC}_{\mathrm{Me}}$ complexes that have been previously used as precursors for the synthesis of nanocrystals [11]. To the best of our knowledge, the present work is the first detailed study of the structures and bonding situation of the complexes Ag-NHE (Scheme 1). We investigated the bonding in complexes Ag-NHE and the electronic structure of the molecules was analyzed with charge- and energy decomposition methods. A schematic representation of the bonding in $\mathrm{AgCl} \leftarrow \mathrm{NHE}_{\mathrm{Me}}$ with $\sigma$-donors and $\pi$-donors of interactions is suggested. We hope that the information of bonding in complexes Ag-NHE is suitable targets for synthesis.

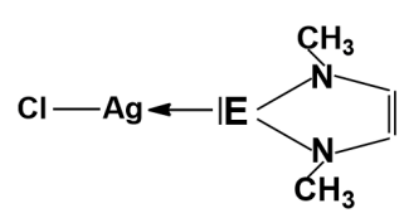

a)

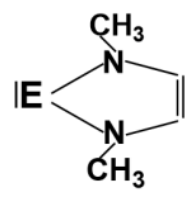

b)
Scheme 1: Overview of the compounds investigated in the present work: a) Complexes $\left[\mathrm{AgCl}-\left\{\mathrm{NHE}_{\mathrm{Me}}\right\}\right]$ $\left(\right.$ Ag-NHE) and b) Ligand $\mathrm{NHE}_{\mathrm{Me}}(\mathbf{N H E})$ with $\mathrm{E}=\mathrm{C}$ $-\mathrm{Pb}$

\section{COMPUTATIONAL METHODS}

Geometry optimizations of the molecules were carried out without symmetry constraints using Gaussian 09 optimizer together with Turbomole 7.0 energies and gradients at the BP86/def2-SVP level of theory. Single point calculations with the same functional but the larger def2-TZVPP basis set and effective core potentials (ECPs) were examined to represent the innermost electrons of $\mathrm{Ag}$ atom as well as the electrons core of the heavier group-14 atoms $\mathrm{Sn}$ and $\mathrm{Pb}$ on the structures derived on BP86/SVP level of theory. The natural bond orbital (NBO) analysis was carried out with the internal module of Gaussian 09 at the BP86/def2-TZVPP//BP86/def2SVP level of theory. For bonding analysis in term of energy decomposition analysis, the geometries of the molecules were re- optimized with the program package ADF 2013.01 with BP86 in conjunction with a triple-zeta-quality basis set using uncontracted Slater-type orbitals (STOs) augmented by two sets of polarization function, with a frozencore approximation for the core electrons. An auxiliary set of $s, p, d, f$ and $g$ STOs were used to fit the molecular densities and to represent the Coulomb and exchange potentials accurately in each SCF cycle. Scalar relativistic effects were incorporated by applying the zeroth-order regular approximation (ZORA). The calculations have been carried out at the BP86/TZ2P+ level of theory that was used for the bonding analyses in term of the EDA - NOCV method.

\section{RESULTS AND DISCUSSION}

\subsection{Structures and energies}

Figure 1 shows the optimized geometries of the parent compounds $\mathbf{A g}-\mathbf{N H C}-\mathbf{A g}-\mathbf{N H P b}$ at the BP86/SVP level together with the most important bond lengths, bending angles, and bond dissociation energies (BDEs). There are no experimental values available for the complexes Ag-NHC to Ag-NHPb. The theoretically predicted Ag-E bond length of AgNHE complexes increased from 2.058 to $2.773 \AA$. The fact was that the related complexes of $\mathrm{N}$ heterocyclic carbene and slightly heavier homologues $\left(\mathrm{NHE}_{\mathrm{Me}}\right.$ and $\mathrm{NHE}_{\mathrm{H}}$ with $\left.\mathrm{E}=\mathrm{C}, \mathrm{Si}, \mathrm{Ge}\right)$ such as gold(I) chloride $\mathrm{AuCl}$ and copper(I) chloride $\mathrm{CuCl}$ were theoretically investigated in the recent past $[15,16]$. The results showed that the theoretically predicted Au-E bond lengths of complexes AuCl-NHE ${ }_{\mathrm{Me}}$ with $\mathrm{E}=\mathrm{C}-\mathrm{Pb}$ as AuCl$\mathrm{NHC}_{\mathrm{Me}}=1.997$ to AuCl-NHPb $\mathrm{Me}=2.708 \AA$ ) [15]; the bond lengths Au-E of complexes AuCl-NHE with $\mathrm{E}=\mathrm{C}-\mathrm{Ge}$ as $\mathrm{AuCl}-\mathrm{NHC}_{\mathrm{H}}=1.976$ to $\mathrm{AuCl}-$ $\mathrm{NHGe}_{\mathrm{H}}=2.349 \AA$ ) [16] and the bond lengths $\mathrm{Cu}-\mathrm{E}$ of complexes $\mathrm{CuCl}-\mathrm{NHE}$ with $\mathrm{E}=\mathrm{C}-\mathrm{Ge}$ as $\mathrm{CuCl}$ $\mathrm{NHC}_{\mathrm{H}}=1.848$ to $\mathrm{CuCl}-\mathrm{NHGe}_{\mathrm{H}}=2.250 \AA$ A) reported in the previous study [16] are slightly shorter than the bond lengths Ag-E of Ag-NHE complexes in this study. Moreover, we want to compare the theoretically predicted Ag-E bond lengths of the tetrylene complexes Ag-NHC to Ag-NHGe with some experimental results of the related complexes. In general, the theoretically predicted Ag-E bond lengths of Ag-NHE in this study are shorter than the experimental results measured Ag-E bonds of carbene-analogues complexes [17-20]. For example, the carbene complex NHC-AgCl has C-Ag lengths in the range $2.061 \AA$ [17], which is longer than the $\mathrm{C}-\mathrm{Ag}$ bond length in the carbene complex Ag-NHC 
$(2.058 \AA)$. The silylene complex $\left(\mathrm{R}_{2}^{\mathrm{H}} \mathrm{Si}\right)_{2} \mathrm{Ag}$ with $\mathrm{R}$ =1,1,4,4-tetrakis(trimethylsilyl)butane-1,4-diyl [18], as a bicyclic silylene ligand, has Ag-Si bond length of $2.401 \AA$ whereas the $\mathrm{Ag}$-Si bond in the silylene complex Ag-NHSi has a length of $2.317 \AA$ A. The $\left\{\mathrm{LGe}\left[\mathrm{C}\left(\mathrm{SiMe}_{3}\right) \mathrm{N}_{2}\right] \mathrm{AgC}_{6} \mathrm{~F}_{5}\right\}(\mathrm{L}=\mathrm{HC}[\mathrm{C}(\mathrm{Me}) \mathrm{N}-2,6-$ $\left.{ }_{i{ }_{2}} \mathrm{C}_{6} \mathrm{H}_{3}\right]_{2}$ ) [19] has an experimental $\mathrm{Ag}-\mathrm{Ge}$ bond length of $2.448 \AA$, which is also longer than the $\mathrm{Ag}$ Ge bond in Ag-NHGe (2.404 $⿱$ ). . However, the bond length $\mathrm{Ag}$-Sn of complex $\left[\left(\mathrm{Ag}(\mathrm{SCN})\left\{\mathrm{Sn}\left(\mathrm{CHR}_{2}\right)_{2}\right\}\right.\right.$ $\left.\left(\mathrm{OC}_{4} \mathrm{H}_{8}\right)_{2}\right]_{2}$ is $2.598 \AA$ [20] shorter than the stannylene adduct Ag-NHSn has Ag-Sn $=2.602 \AA$. Figure 1 also shows that the examination of the equilibrium geometries of Ag-NHC-Ag-NHPb shows tetrylene ligands NHE are bonded end-on way to $\mathrm{AgCl}$ in the complexes Ag-NHE ( $\mathrm{E}=\mathrm{C}-$ $\mathrm{Sn}$ ) which is the bending angle, $\alpha$, which is $180.0^{\circ}$, while the ligand plumbylene in Ag-NHPb is bonded in a side-on fashion, which is the bending angle, $\alpha$, is $85.0^{\circ}$. Figure 1 gives the theoretically predicted BDEs for Ag-E bonds of Ag-NHC-Ag-NHPb, which exhibit an interesting trend. The calculated bond energies suggest that the Ag-tetrylene ligands bond strength decrease from Ag-NHC $\left(D_{e}=57.3\right.$ $\mathrm{kcal} / \mathrm{mol})$ to $\mathbf{A g}-\mathbf{N H S i}\left(D_{e}=45.2 \mathrm{kcal} / \mathrm{mol}\right)$. There is a continuous strengthening of the BDEs for the heavier ligands from Ag-NHSi $\left(D_{e}=45.2 \mathrm{kcal} / \mathrm{mol}\right)$ to $\mathbf{A g}-\mathbf{N H P b}\left(D_{e}=28.6 \mathrm{kcal} / \mathrm{mol}\right)$. The trend of the theoretically predicted $\mathrm{AgCl}$-tetrylenes BDEs in this study is significantly lower than the calculated values for the gold(I) chloride $\mathrm{AuCl}$ complexes that carry tetrylene ligands (AuCl-NHC $\mathrm{Me}_{\mathrm{Me}}-\mathrm{AuCl}-$ $\mathrm{NHPb}_{\mathrm{Me}}$ ) with the BDEs change from $D_{e}=79.2$ to $42.7 \mathrm{kcal} / \mathrm{mol}$ [15]; and for the gold(I) chloride $\mathrm{AuCl}$ complexes that carry the less bulky slighter tetrylene ligands ( $\mathrm{AuCl}-\mathrm{NHC}_{\mathrm{H}}-\mathrm{AuCl}-\mathrm{NHGe}_{\mathrm{H}}$ ) with the BDEs change from $D_{e}=82.8$ to $49.4 \mathrm{kcal} / \mathrm{mol}$ [16]; and with the copper(I) chloride $\mathrm{CuCl}$ complexes that carry the less bulky slighter tetrylene ligands $(\mathrm{CuCl}-$ $\mathrm{NHC}_{\mathrm{H}}-\mathrm{CuCl}-\mathrm{NHGe}_{\mathrm{H}}$ ), the BDEs decrease from $D_{e}$ $=67.4$ to $35.1 \mathrm{kcal} / \mathrm{mol}$ [16]. The bond length Ag-E of the complexes Ag-NHE was longer than the bond $\mathrm{Au}-\mathrm{E}$ and $\mathrm{Cu}-\mathrm{E}$ of the complexes gold-tetrylene $[15,16]$ and copper-tetrylene [16]. This is quite suitable because the metal-NHE $\mathrm{Me}_{\mathrm{e}}$ interactions of $\mathrm{NHE}_{\mathrm{Me}}-\mathrm{AgCl}$ have small $\mathrm{NHE}_{\mathrm{Me}} \leftarrow \mathrm{AgCl} \pi$-backdonation in complexes. From this, it follows that the silver donor-acceptor complexes with carbene, silylene, and germylene ligands can have very strong bonds and the appearance of a small contribution in free ligands $\leftarrow \mathrm{AgCl} \pi$-back-donation in complexes which will be further explained in bonding analysis.

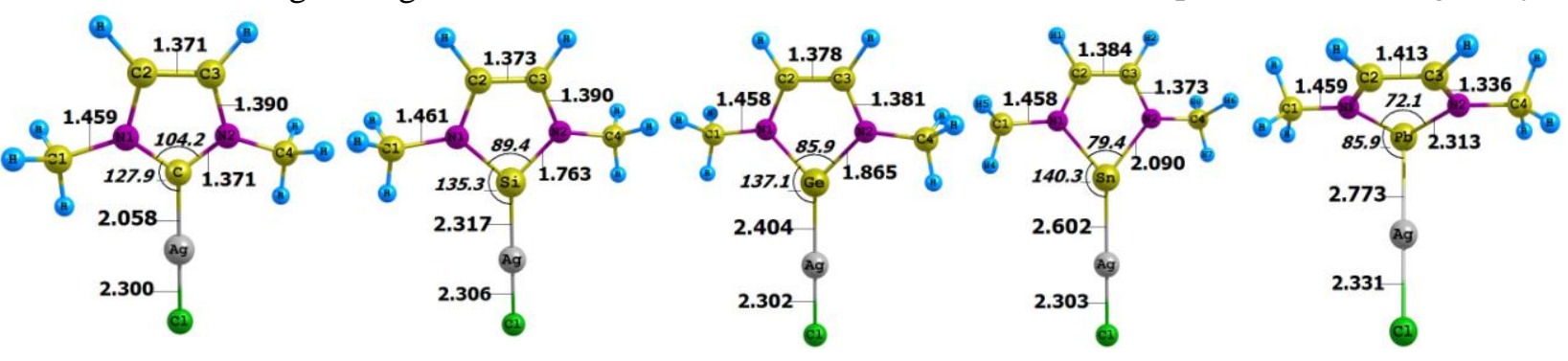

Ag-NHC

Ag-NHSi

Ag-NHGe

Ag-NHSn

$\alpha=180.0^{\circ} ; D_{e}=57.3 \quad \alpha=180.0^{\circ} ; D_{e}=45.2 \quad \alpha=180.0^{\circ} ; D_{e}=35.1 \quad \alpha=180.0^{\circ} ; D_{e}=27.6$

$\alpha=85.0^{\circ} ; D_{e}=28.6$

Figure 1: Optimized geometries of complexes Ag-NHC-Ag-NHPb at the BP86/def2-SVP level. Bond lengths are given in $\AA$; angles in degrees. Calculated bond dissociation energy, $D_{e}(\mathrm{kcal} / \mathrm{mol})$, for the ligand$\mathrm{AgCl}$ bonds in complexes at the BP86/def2-TZVPP//BP86/def2-SVP level. The bending angles, $\alpha$, are the angles X-E-Ag where $\mathrm{X}$ is the midpoint between the N-N distances:

\subsection{BONDING ANALYSIS}

Table 1 gives results of the NBO calculations for parent compounds Ag-NHC-Ag-NHPb. The calculated partial charges show that the $\mathrm{AgCl}$ fragment in the complexes always carries a negative charge, which increases from Ag-NHC (-0.28 e) to Ag-NHPb (-0.37 e), except the value of Ag-NHSi is -0.37 e. The Wiberg bond orders for the Ag-E bond in Ag-NHE increases from Ag-NHC (0.59) to AgNHSi (0.77), but then decreases from Ag-NHSi to
Ag-NHPb (0.44). We would like to comment on the partial atomic charges of the donor atoms $\mathrm{E}$ and the acceptor atom Ag in the complexes Ag-NHE. The silver atom always carries a positive charge between $0.21 \mathrm{e}(\mathrm{E}=\mathrm{Si})$ and $0.31 \mathrm{e}(\mathrm{E}=\mathrm{C})$. The carbon donor atom in Ag-NHC has a small positive charge of 0.11 e while the heavier atoms have a large positive charge between 0.75 e $(\mathrm{E}=\mathrm{Pb})$ and $1.08 \mathrm{e}(\mathrm{E}=\mathrm{Si})$. The unusually smallest Wiberg bond order value of Ag-C bond in complex Ag-NHC can be explained by the shortest bond length and possibly due to the 
shortest $\mathrm{Ag}-\mathrm{C}$ bond length with the more bulky substituent $\mathrm{CH}_{3}$ groups in the $\mathrm{NHE}_{\mathrm{Me}}$ moieties of the tetrylene ligands. Note that the partial charge value of $\mathrm{AgCl}$ in complex $\mathbf{A g}-\mathbf{N H S i}$ also exhibits the large negatively charge $(-0.37 \mathrm{e})$. We realize that the trend of the partial charges does not support the suggestion that there is a change from ligand donation $[\mathrm{Ag}] \rightarrow \mathrm{NHE}_{\mathrm{Me}}$ for the head-on bonded lighter homologues to metal donation $[\mathrm{Ag}] \rightarrow \mathrm{NHE}_{\mathrm{Me}}$ for the side-on bonded adduct.

Table 1: NBO results with Wiberg bond indices (WBI) and natural population analysis (NPA) at the BP86/def2-TZVPP//BP86/def2-SVP level for complexes Ag-NHC-Ag-NHPb. The partial charges, $q$, are given in electrons [e]

\begin{tabular}{|l|l|c|c|c|c|}
\hline \multicolumn{1}{|c|}{ Molecule } & Bond & WBI & $q[\mathrm{AgCl}]$ & $\mathrm{Atom}$ & NPA $(q)$ \\
\hline Ag-NHC & $\mathrm{Ag}-\mathrm{C}$ & 0.59 & -0.28 & $\mathrm{Ag}$ & 0.31 \\
& $\mathrm{C}-\mathrm{N} 1$ & 1.27 & & $\mathrm{C}$ & 0.11 \\
& $\mathrm{C}-\mathrm{N} 2$ & 1.27 & & $\mathrm{~N}$ & -0.31 \\
& $\mathrm{Ag}-\mathrm{Cl}$ & 0.65 & & $\mathrm{Cl}$ & -0.59 \\
\hline Ag-NHSi & $\mathrm{Ag}-\mathrm{Si}$ & 0.77 & -0.37 & $\mathrm{Ag}$ & 0.21 \\
& $\mathrm{Si}-\mathrm{N} 1$ & 0.83 & & $\mathrm{Si}$ & 1.08 \\
& $\mathrm{Si}-\mathrm{N} 2$ & 0.83 & & $\mathrm{~N}$ & -0.70 \\
& $\mathrm{Ag}-\mathrm{Cl}$ & 0.65 & & $\mathrm{Cl}$ & -0.58 \\
\hline Ag-NHGe & $\mathrm{Ag}-\mathrm{Ge}$ & 0.63 & -0.30 & $\mathrm{Ag}$ & 0.27 \\
& $\mathrm{Ge}-\mathrm{N} 1$ & 0.80 & & $\mathrm{Ge}$ & 0.99 \\
& $\mathrm{Ge}-\mathrm{N} 2$ & 0.80 & & $\mathrm{~N}$ & -0.68 \\
& $\mathrm{Ag}-\mathrm{Cl}$ & 0.66 & & $\mathrm{Cl}$ & -0.57 \\
\hline Ag-NHSn & $\mathrm{Ag}-\mathrm{Sn}$ & 0.57 & -0.31 & $\mathrm{Ag}$ & 0.26 \\
& $\mathrm{Sn}-\mathrm{N} 1$ & 0.73 & & $\mathrm{Sn}$ & 1.01 \\
& $\mathrm{Sn}-\mathrm{N} 2$ & 0.73 & & $\mathrm{~N}$ & -0.66 \\
& $\mathrm{Ag}-\mathrm{Cl}$ & 0.67 & & $\mathrm{Cl}$ & -0.57 \\
\hline \multirow{2}{*}{ Ag-NHPb } & $\mathrm{Ag}-\mathrm{Pb}$ & 0.44 & -0.37 & $\mathrm{Ag}$ & 0.23 \\
& $\mathrm{~Pb}-\mathrm{N} 1$ & 0.57 & & $\mathrm{~Pb}$ & 0.75 \\
& $\mathrm{~Pb}-\mathrm{N} 2$ & 0.57 & & $\mathrm{~N}$ & -0.54 \\
& $\mathrm{Ag}-\mathrm{Cl}$ & 0.60 & & $\mathrm{Cl}$ & -0.61 \\
\hline
\end{tabular}

As pointed out in the computational details, the molecules have $\mathrm{C} 1$ symmetry with no genuine $\sigma$ and $\pi$ orbitals since there is no mirror plane in the molecular structure. We consider the strength of the $\pi$ donation $\mathrm{NHE}_{\mathrm{Me}} \rightarrow \mathrm{AgCl}$ which may be expected from the $\sigma-$ and $\pi$ lone-pair orbital of the ligand $\mathrm{NHE}_{\mathrm{Me}}$ into the second vacant coordination side of metal fragment $\mathrm{AgCl}$, we have to keep visually the shapes of $\mathbf{A g}-\mathbf{N H P b}$ in one plane to identify $\sigma$ - and $\pi$-type molecular orbitals. Figure 2 shows two occupied molecular orbitals and orbital energies of $\sigma$-type and $\pi$-type MOs from Ag-NHC-Ag-NHPb at the BP86/TZVPP level. The energy level of the $\pi$ type donor orbital of Ag-NHSi-Ag-NHPb is higher lying than the $\sigma$-type donor orbital whereas the energy level of the $\pi$-type donor orbital from AgNHC is lower lying than the $\sigma$-type donor orbital. Note that the shape of the $\sigma$ - and $\pi$-orbitals (HOMO11 and HOMO-10) of complex Ag-NHPb is significantly different from the shapes of the slighter homologues Ag-NHE $(\mathrm{E}=\mathrm{C}-\mathrm{Sn})$. This can be explained by a detailed insight into the bonding situation of the side-on bonded plumbylene Ag-
NHPb where the bending angle $\alpha$ is bonded in the strongest side-on mode $\left(\alpha=85.0^{\circ}\right)$. Especially, the shape of the molecular orbitals indicates that $\mathrm{NHE}_{\mathrm{Me}} \rightarrow \mathrm{AgCl}$ not only has significant $\sigma$ donation but also exhibits a bit $\pi$ donation in complexes. We can explain that the $\pi$ donation in complexes is due to the strong $\mathrm{N} \rightarrow \mathrm{E} \pi$ donation at the ring of the $\mathrm{NHE}_{\mathrm{Me}}$ ligands.

We want to point out that the orbitals at the $\mathrm{Ag}$ side carry a little $\mathrm{NHE}_{\mathrm{Me}} \leftarrow \mathrm{AuCl}$ back-donation and mainly exhibit $\mathrm{NHE}_{\mathrm{Me}} \rightarrow \mathrm{AuCl} \sigma$-donation. We suggest the Scheme 2 with the Scheme 2 (d) firstly shows an orbital diagram of N-heterocyclic carbenes and analogues and bonds of NHE to Ag center. We realize that the nitrogen in the ring $\mathrm{NHE}_{\mathrm{Me}}$ can act as ligands which indicate $\mathrm{N} \rightarrow \mathrm{E}$ donation and the $\mathrm{NHE}_{\mathrm{Me}}$ ligands have the resonance form for molecules which exhibits the orbital overlap between the $\pi$-type lone pair and the N-E $\pi^{*}$-orbitals which exhibits in more electron density at $\mathrm{E}$ atom which is shown in Scheme 2 (a) and Scheme 2 (b). Furthermore, Scheme 3 also shows that Nheterocyclic tetrylene $\mathrm{NHE}_{\mathrm{Me}}$ in which the central $\mathrm{E}$ 
atom can have two lone pairs may show the characteristics of an $\mathrm{E}(0)$ compounds with $\mathrm{E}=\mathrm{C}, \mathrm{Si}$, $\mathrm{Ge}, \mathrm{Sn}, \mathrm{Pb}$ (Scheme 2 (b)). The resonance form may be ignored due to the $\pi$-type lone pair is delocalized; this leads to the loss of aromaticity. Moreover, Schemes 2 (b, c, d) also exhibit a back-donation from metal fragment to $\mathrm{E}$ atom of ligand tetrylene.

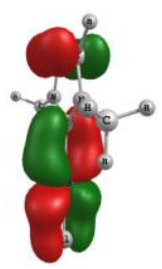

$\operatorname{Ag-NHC}(\pi)$

HOMO-9

$-7.946(\mathrm{eV})$

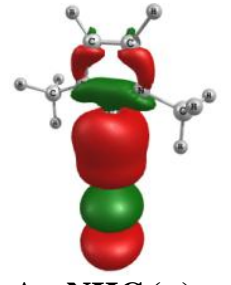

$\operatorname{Ag}-\mathrm{NHC}(\sigma)$

HOMO-4

$-6.830(\mathrm{eV})$

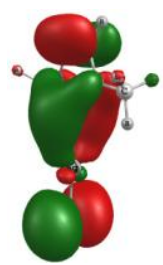

$\operatorname{Ag}-\mathrm{NHSi}(\pi)$

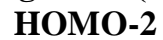

$-5.878(\mathrm{eV})$

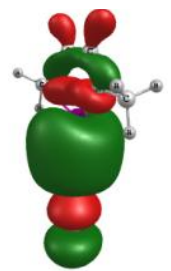

$\operatorname{Ag}-\mathrm{NHSi}(\sigma)$

HOMO-4

$-7.265(\mathrm{eV})$

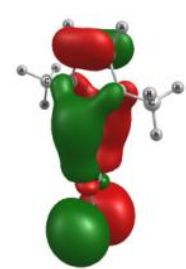

$\operatorname{Ag}-\operatorname{NHGe}(\pi)$

HOMO-2

$-5.850(\mathrm{eV})$

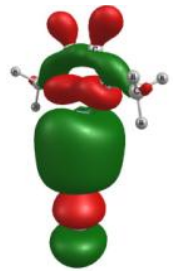

$\operatorname{Ag-NHGe}(\sigma)$

HOMO-5

$-7.483(\mathrm{eV})$

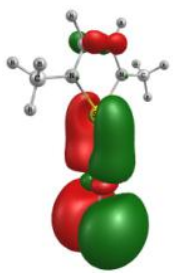

$\operatorname{Ag}-\operatorname{NHSn}(\pi)$

HOMO-2

$-5.878(\mathrm{eV})$

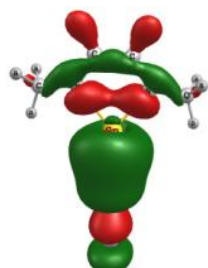

$\operatorname{Ag}-N_{H S n}(\sigma)$

HOMO-5

$-7.565(\mathrm{eV})$

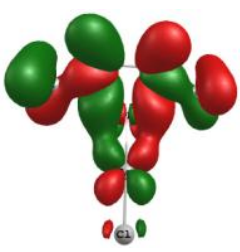

$\operatorname{Ag}-\mathrm{NHPb}(\pi)$

HOMO-10

$-8.109(\mathrm{eV})$

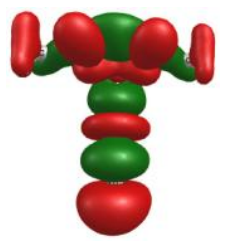

$\operatorname{Ag}-\mathrm{NHPb}(\sigma)$

HOMO-11

$-8.436(\mathrm{eV})$

Figure 2: Molecular orbitals and orbital energies of $\sigma$-type and $\pi$-type in Ag-NHC-Ag-NHPb at the BP86/def2-TZVPP level. Orbital energies are given in eV

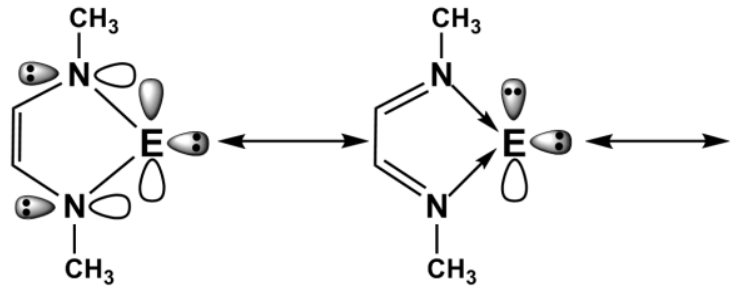

(a)

(b)

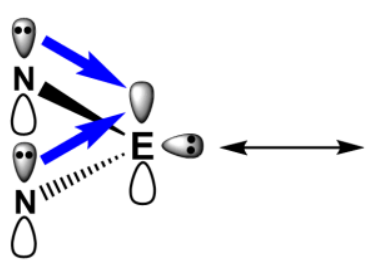

(c)

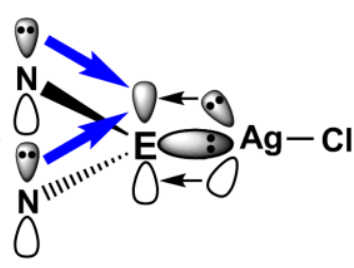

(d)

Scheme 2: Suggested schematic representation of $\mathrm{NHE}_{\mathrm{Me}}$ showing: a) Divalent element $\mathrm{E}$ (II) character (tetrylenes); b) Divalent element $\mathrm{E}(0)$ character with the 2 lone pairs at $\mathrm{E}$ atom; b) and c) Correspondent possible resonance forms of element $\mathrm{E}(\mathrm{II})$ and element $\mathrm{E}(0)$ ligands showing the divalent element $\mathrm{E}$ (II) and the divalent element $\mathrm{E}(0)$ characters with $\mathrm{E}=\mathrm{C}-\mathrm{Pb}$; d) Bonding of $\mathrm{NHE}_{\mathrm{Me}}$ ligand to metal fragment $\mathrm{AgCl}$

In order to give a detailed insight into the bonding situation of complexes, we analyzed the nature of the donor-acceptor interactions in AgNHE with the EDA in conjunction with the NOCV method. Table 2 gives the numerical results of the Ag-NHE interactions at the BP86/TZ2P+ level. The trend of the bond dissociations energies (BDEs), $\Delta E$ $\left(=-D_{e}\right)[\mathrm{kcal} / \mathrm{mol}]$, for the Ag-E bond in Ag-NHE system decrease from the lighter to the heavier homologues (Ag-NHC: $-D_{e}=-55.0 \mathrm{kcal} / \mathrm{mol}$; $\mathbf{A g}$ NHPb: $\left.-D_{e}=-27.5 \mathrm{kcal} / \mathrm{mol}\right)$. The decrease of the BDEs from the lighter to heavier adduct is determined by the intrinsic strength of the metalligand bonds $\Delta E_{\text {int }}$ in which the intrinsic energy $\Delta E_{\text {int }}$ values decreases from $-55.7 \mathrm{kcal} / \mathrm{mol}$ (Ag-NHC) to $29.5 \mathrm{kcal} / \mathrm{mol}$ (Ag-NHPb) of the system. The preparation energy $\Delta E_{\text {prep }}$ of complexes changes from 0.7 in $\mathbf{A g}-\mathbf{N H C}$ to $2.0 \mathrm{kcal} / \mathrm{mol}$ in $\mathbf{A g - N H P b}$. The three main terms Pauli repulsion $\Delta E_{\text {Pauli }}$, electrostatic interaction $\Delta E_{\text {elstat }}$, and orbital interaction $\Delta E_{\text {orb }}$ are considered to inspect their contribution to the intrinsic energy $\Delta E_{\text {int }}$ of the complexes. Inspection of the three main terms indicated that the Pauli repulsion $\Delta E_{\text {Pauli }}$ has the largest value of $132.7 \mathrm{kcal} / \mathrm{mol}$ for $\mathbf{A g}-\mathbf{N H C}$ and gets smaller from $\mathrm{E}=\mathrm{C}$ to $\mathrm{E}=\mathrm{Pb}(48.0 \mathrm{kcal} / \mathrm{mol})$. We realized that the decrease of the BDEs from the 
lighter to heavier adduct is determined by the electrostatic strength of the metal-ligand bonds $\Delta E_{\text {elstat }}$. The electrostatic strength $\Delta E_{\text {elstat }}$ of Ag-NHE decreases from Ag-NHC (-146.2 kcal/mol) to AgNHSi (-119.9 $\mathrm{kcal} / \mathrm{mol})$, then Ag-NHGe (-79.2 $\mathrm{kcal} / \mathrm{mol})$, Ag-NHSn (-59.7 kcal/mol), and then AgNHC $(-45.3 \mathrm{kcal} / \mathrm{mol})$. Table 2 also shows that the contribution of $\Delta E_{\sigma}$ to $\Delta E_{\text {orb }}$ was rather large for all complexes where the values were between $65.5-$ $85.5 \%$. Thus, the EDA-NOCV calculations show that the Ag-E bonding in the complexes Ag-NHCAg-NHPb has a small contribution which may come from $\mathrm{NHE}_{\mathrm{Me}} \rightarrow \mathrm{AgCl} \pi$-donation and $\mathrm{NHE}_{\mathrm{Me}} \leftarrow \mathrm{AgCl}$ $\pi$-back-donation.

Table 2: EDA-NOCV results with interaction energy $\left(\Delta E_{\text {int }}\right)$ and their components $\left(\Delta E_{\text {Pauli }}, \Delta E_{\text {elstat }}, \Delta E_{\text {orb }}\right)$ at the $\mathrm{BP} 86 / \mathrm{TZ2} \mathrm{P}+$ level for compound $\mathbf{A g}-\mathbf{N H C}-\mathbf{A g}-\mathbf{N H P b}$ using the moieties $[\mathrm{AgCl}]$ and $\left[\mathrm{NHE}_{\mathrm{Me}}\right]$ as interacting fragments. The complexes are analyzed with $\mathrm{C} 1$ symmetry. All values in $\mathrm{kcal} / \mathrm{mol}$

\begin{tabular}{|c|c|c|c|c|c|}
\hline Compound & Ag-NHC & Ag-NHSi & Ag-NHGe & Ag-NHSn & Ag-NHPb \\
\hline Fragment & $\begin{array}{c}\mathrm{AgCl} \\
\mathrm{NHC}_{\mathrm{Me}}\end{array}$ & $\begin{array}{c}\mathrm{AgCl} \\
\mathrm{NHSi}_{\mathrm{Me}}\end{array}$ & $\begin{array}{c}\mathrm{AgCl} \\
\mathrm{NHGe}_{\mathrm{Me}}\end{array}$ & $\begin{array}{c}\mathrm{AgCl} \\
\mathrm{NHSn}_{\mathrm{Me}}\end{array}$ & $\begin{array}{c}\mathrm{AgCl} \\
\mathrm{NHPb}_{\mathrm{Me}}\end{array}$ \\
\hline$\Delta E_{\text {int }}$ & -55.7 & -44.6 & -34.0 & -28.4 & -29.5 \\
\hline$\Delta E_{\text {Pauli }}$ & 132.7 & 117.7 & 79.8 & 61.8 & 48.0 \\
\hline$\Delta E_{\text {elstat }}^{\text {[a] }}$ & $-146.2(77.6 \%)$ & $-119.9(73.9 \%)$ & $-79.2(69.6 \%)$ & $-59.7(66.2 \%)$ & $-45.3(58.4 \%)$ \\
\hline$\Delta E_{o r b}^{[\mathrm{a}]}$ & $-42.2(22.4 \%)$ & $-42.4(26.1 \%)$ & $-34.6(30.4 \%)$ & $-30.5(33.8 \%)$ & $-32.3(41.6 \%)$ \\
\hline$\Delta E_{\sigma}^{[\mathrm{b}]}$ & $-29.6(70.1 \%)$ & $-27.8(65.5 \%)$ & $-24.2(70.0 \%)$ & $-22.6(74.1 \%)$ & $-27.6(85.5 \%)$ \\
\hline$\Delta E_{\pi}^{[\mathrm{b}]}$ & $-10.4(24.6 \%)$ & $-13.3(31.3 \%)$ & $-9.3(26.8 \%)$ & $-6.7(22.1 \%)$ & $-3.1(9.5 \%)$ \\
\hline$\Delta E_{\text {rest }}^{[\mathrm{b}]}$ & $-2.2(5.3 \%)$ & $-1.3(3.2 \%)$ & $-1.1(3.2 \%)$ & $-1.2(3.8 \%)$ & $-1.6(5.0 \%)$ \\
\hline$\Delta E_{\text {prep }}$ & 0.7 & 1.3 & 1.1 & 1.0 & 2.0 \\
\hline$\Delta E\left(=-D_{e}\right)^{[\mathrm{c}]}$ & $-55.0(-57.3)^{[\mathrm{c}]}$ & $-43.3(-45.2)^{[\mathrm{c}]}$ & $-32.9(-35.1)^{[\mathrm{c}]}$ & $-27.4(-27.6)^{[\mathrm{c}]}$ & $-27.5(-28.6)^{[\mathrm{c}]}$ \\
\hline
\end{tabular}

[a] The relative percentage contributions to the total attractive interaction $\Delta E_{\text {elstat }}+\Delta E_{\text {orb }}$

${ }^{[b]}$ The relative percentage contributions to the total orbital interaction $\Delta E_{\text {orb }}$ are given in parentheses

${ }^{[c]}$ The values in parentheses give the dissociation energy at the BP86/def2-TZVPP//BP86/def2-SVP level.

We continue determining the charge transfer between the donor and acceptor fragments by plotting of the pairs of orbitals, the associated deformation densities, and stabilization energies. The $\Delta E_{\text {orb }}$ term was examined of the EDA-NOCV results further in order to obtain more detailed information on the nature of the bonding in AgNHC-Ag-NHPb. The plots of the pairs of orbitals $\Psi_{-k} / \Psi_{k}$ that yield the NOCVs providing the largest contributions to the $\sigma$ - and $\pi$-orbital terms $\Delta E_{\sigma}$ and $\Delta E_{\pi}$ in $\mathbf{A g}$-NHE $(\mathrm{E}=\mathrm{C}, \mathrm{Pb})$ and the associated deformation densities $\Delta \rho$ and stabilization energies are shown in Figure 3. The shape of orbital pairs in Ag-NHE (E = Si - Sn) exhibits the head-on mode between $\mathrm{NHE}_{\mathrm{Me}}$ and $\mathrm{AgCl}$, exhibit similar shapes to those of adduct $\mathbf{A g}-\mathbf{N H C}$ and therefore, they are not shown in Figure 3. Note that the yellow/blue colors in the figures for $\Psi_{-k} / \Psi_{k}$ indicate the sign of the orbitals, and the red/white colors in the deformation density $\Delta \rho$ designate charge depletion and the white areas point to charge accumulation. The charge flow $\Delta \rho$ occurs in the direction from red to white. Figures 3 (a) and 3 (c) give the NOCV pairs of $\sigma$-orbitals for Ag-NHC. The EDA-NOCV results give the effort to understand the nature of chemical bonding in tetrylene with the nitrogen atoms in $\mathrm{NHE}_{\mathrm{Me}}$ ring has effects to donor moieties. Figure 3 (a) and 3 (c) shows that the $\sigma$ - type interaction is clearly from the donating $\mathrm{NHC}_{\mathrm{Me}}$ fragment to the accepting $\mathrm{AgCl}$ fragment. The shapes of the NOCV pairs $\Psi_{-2} / \Psi_{2}$ and the deformation density $\Delta \rho_{2}$ in Figure 3 (b) show that stabilization of $-6.5 \mathrm{kcal} / \mathrm{mol}$ can be assigned to $\mathrm{ClAg} \rightarrow \mathrm{NHC}_{\mathrm{Me}} \pi$-donation while the stabilization of also comes from the relaxation of the acceptor fragment $\mathrm{AgCl}$ in Ag-NHC. Figures 3-(d, e, f) show significantly different EDA-NOCV results for AgNHPb because of the surprising structure of the plumbylene ligand $\mathbf{N H P b}$, which is bonded through its $\pi$-electron density. Note that the structures and orbitals pairs of the lighter homologues Ag-NHE with $\mathrm{E}=\mathrm{C}-\mathrm{Sn}$ have head-on modes between the ligands and $\mathrm{AgCl}$, whereas the heavier species Ag$\mathbf{N H P b}$ exhibit a side-on bonded ligands to the $\mathrm{AgCl}$ fragment. Figure 3 (d) clearly shows that the $\sigma$-type interaction has the direction of the charge flow of $\mathrm{ClAg} \leftarrow \mathrm{NHPb}_{\mathrm{Me}}$. The deformation density $\Delta \rho_{l}$ exhibits an area of charge donation (red area) at the $\mathrm{NHPb}_{\mathrm{Me}}$ moiety associated with the deformation density $\Delta \rho_{l}$ and stabilization energy is -24.9 $\mathrm{kcal} / \mathrm{mol}$. Figures 3 (f) shows that the very weak $\pi$ - 
type orbital interactions in Ag-NHPb come from typical $\pi$-back-donation $\mathrm{ClAg} \rightarrow \mathrm{NHPb}_{\mathrm{Me}}$ with the charge flow $\Psi_{-3} / \Psi_{3}$ indicates stabilization of -1.5 $\mathrm{kcal} / \mathrm{mol}$. Thus, the bonding in the tetrylene complexes $\mathbf{A g}-\mathbf{N H E}_{\mathbf{M e}}$ exhibits the typical feature regarding strong $\sigma$-donation and weak $\pi$-backdonation. From the above results, it can be asserted that the weaker bonds of the heavier complexes $\left[\mathrm{AgCl}-\left\{\mathrm{NHE}_{\mathrm{Me}}\right\}\right]$ result from a strong decrease in the electrostatic component of the W-E bonds. The $\pi$-interactions in $\left[\mathrm{AgCl}-\left\{\mathrm{NHE}_{\mathrm{Me}}\right\}\right]$ are due to very weak $\pi$-back-donation and are also irrelevant for the bond strength. The ligand $\leftarrow A g \pi$-back-donation in the complexes is very small and the Ag-ligand bonds have a strong ionic character which comes the electrostatic attraction between the positively charged $\mathrm{Ag}$ atom and the $\sigma$-electron pair of the $\mathrm{E}$ donor atom.

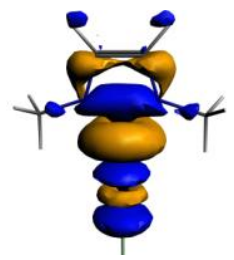

$\Psi_{-1}(-0.43)$

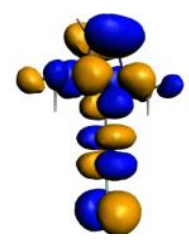

$\Psi_{-2}(-0.27)$

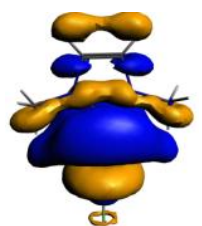

$\Psi_{-3}(-0.17)$
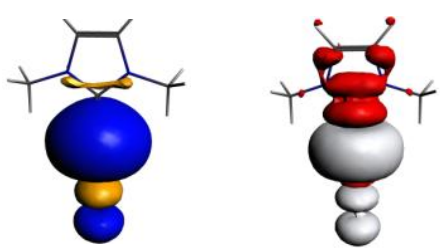

$\operatorname{Ag-NHC}(\sigma)$

$\Psi_{1}(0.43)$

$\Delta \rho_{1}(\Delta \mathrm{E}=-22.8)(\mathbf{a})$
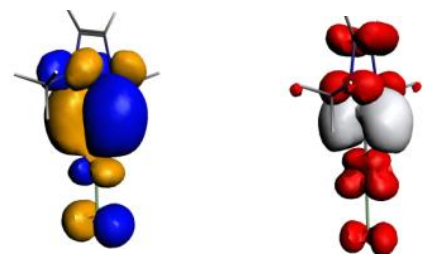

$\operatorname{Ag}-\mathrm{NHC}(\pi)$

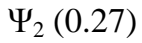

$\Delta \rho_{2}(\Delta \mathrm{E}=-6.5)(\mathbf{b})$

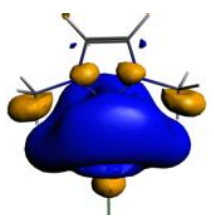

$\operatorname{Ag-NHC}(\sigma)$

$\Psi_{3}(0.17)$

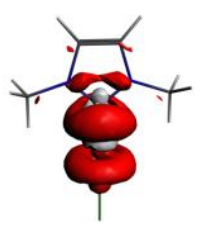

) (c)
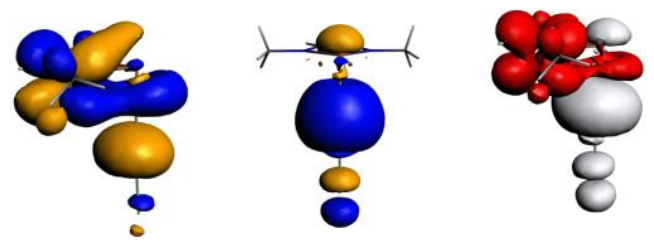

$\Psi_{-1}(-0.60)$

Ag-NHPb $(\sigma)$

$\Psi_{1}(0.60)$

$\Delta \rho_{1}(\Delta \mathrm{E}=-24.9)(\mathbf{d})$
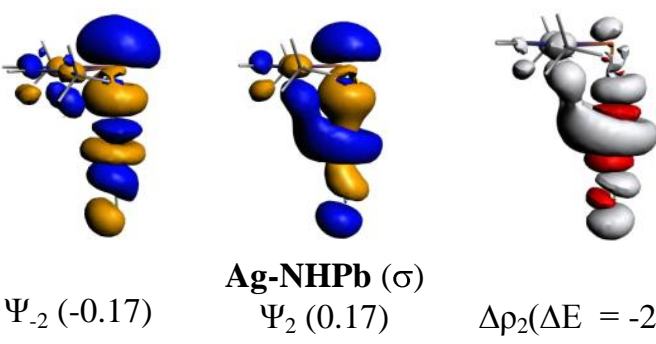

$\operatorname{Ag}-\mathbf{N H P b}(\sigma)$

$\Psi_{2}(0.17)$

$\Delta \rho_{2}(\Delta \mathrm{E}=-2.8)(\mathbf{e})$

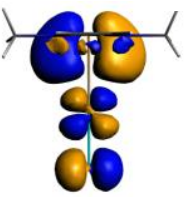

$\Psi_{-3}(-0.16)$

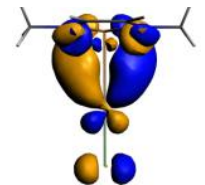

$\operatorname{Ag}-\mathbf{N H P b}(\pi)$

$\Psi_{3}(0.16)$

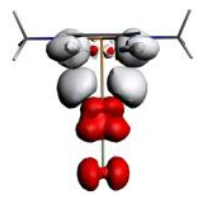

$\Delta \rho_{3}(\Delta \mathrm{E}=-1.5)(\mathbf{f})$

Figure 3: Most important NOCV pairs of orbitals $\Psi_{-k}, \Psi_{k}$ with their eigenvalues $-v_{k i}, v_{k}$ given in parentheses, and the associated deformation densities $\Delta \rho_{k}$ and orbital stabilization energies $\Delta E$ for the complexes $\mathbf{A g}$ -

$\mathbf{N H C}$ and Ag-NHPb. The charge flow in the deformation densities is from the red $\rightarrow$ white region. (a),

(c) $\sigma$-NOCVs of Ag-NHC; (b) $\pi$-NOCV of Ag-NHC; (d), (e) $\sigma$-NOCVs Ag-NHPb; (f) $\pi$-NOCV of Ag-NHPb. Energy values in $\mathrm{kcal} / \mathrm{mol}$

\section{CONCLUSIONS}

DFT calculations find that the equilibrium structures of the Ag-NHE show major differences in the bonded orientation of NHPb ligand in Ag-NHPb compared with NHE ligands the slighter homologues Ag-NHE (E= C-Sn). The BDE results show that the Ag-carbene bond in Ag-NHC is very strong bond and decreases from the slighter to the heavier homologues with the order is Ag-NHC > Ag-NHSi > Ag-NHGe > Ag-NHSn $\approx$ Ag-NHPb. Bonding analysis shows that ligands NHE exhibit donor-acceptor bonds with the $\sigma$ lone pair electrons of NHE donated into the vacant orbital of the metal fragment $\mathrm{AgCl}$ and the ligands NHE are strong $\sigma$ - donors and very weak $\pi$ donor and the NOCV pairs of the bonding show small $\pi$-back donation from the Ag to the NHE ligands. A comprehensive study in the above complexes is needed to give important information to experimentalists about stabilities and properties of as-yet detailed unsynthesized heavier adducts (Ag-NHSi-Ag-NHPb).

Acknowledgements. Nguyen Thi Ai Nhung thanks Prof. Dr. Gernot Frenking for allowing the continuous use of her own resources within Frenking's group. The programs of the studies were run via the Erwin/Annemarie clusters operated by Reuti at Philipps-Universität Marburg-Germany. This research is funded by Vietnam National 
Foundation for Science and Technology Development (NAFOSTED) under grant number 104.06-2014.13.

\section{REFERENCES}

1. E. O. Fischer, A. Maasbol. On the Existence of a Tungsten Carbonyl Carbene Complex, Angew. Chem. Int. Ed. Engl., 3, 580-581(1964).

2. D. Nemcsok, K. Wichmann, G. Frenking. The Significance of $\pi$ Interactions in Group 11 Complexes with $\mathrm{N}$-Heterocyclic Carbenes, Organometallics, 23, 3640-3646 (2004).

3. S. Zhu, R. Liang, H. Jiang. A direct and practical approach for the synthesis of $N$-heterocyclic carbene coinage metal complexes, Tetrahedron, 68, 79497955 (2012).

4. A. C. Sentman S. Csihony, R. M. Waymouth, J. L. Hedrick. Silver(I)-Carbene Complexes/Ionic Liquids: Novel N-Heterocyclic Carbene Delivery Agents for Organocatalytic Transformations, J. Org. Chem., 70, 2391-2393 (2005).

5. I. J. B. Lin, C. S. Vasam. Silver(I) N-heterocyclic carbenes, Comment. Inorg. Chem., 25, 75-129 (2004).

6. J. C. Garrison, W. J. Youngs. Ag(I) N-Heterocyclic Carbene Complexes: Synthesis, Structure, and Application, Chem. Rev., 105, 3978-4008 (2005). 11

7. A. Kascatan-Nebioglu M. J. Panzner, C. A. Tessier, C. L. Cannon, W. J. Youngs. N-Heterocyclic carbene-silver complexes: A new class of antibiotics, Coord. Chem. Rev., 251, 884-895 (2007).

8. E. C. Hurst K. Wilson, I. J. S. Fairlamb, V. Chechik. $\mathrm{N}$-Heterocyclic carbene coated metal nanoparticles, New J. Chem., 33, 1837-1840 (2009).

9. C. J. Serpell J. Cookson, A. L. Thompson, C. M. Brown, P. D. Beer. Haloaurate and halopalladate imidazolium salts: structures, properties, and use as precursors for catalytic metal nanoparticles, Dalton Trans., 42, 1385-1393 (2013).

10. X. Ling N. Schaeffer, S. Roland, M. Pileni. Nanocrystals: Why Do Silver and Gold NHeterocyclic Carbene Precursors Behave Differently? Langmuir, 29, 12647-12656 (2013).

11. C. K. Lee C. S. Vasam, T. W. Huang, H. M. J. Wang,
R. Y. Yang, C. S. Lee, I. J. B. Lin. Silver(I) NHeterocyclic Carbenes with Long N-Alkyl Chains, Organometallics, 25, 3768-3775 (2006).

12. O. Kühl. Sterically induced differences in $N$ heterocyclic carbene transition metal complexes, Coord. Chem. Rev., 253, 2481-2492 (2009).

13. M. Melaimi, M. Soleilhavoup, G. Bertrand. Stable Cyclic Carbenes and Related Species beyond Diaminocarbenes, Angew. Chem. Int. Ed., 49, 88108849 (2010).

14. T. A. N. Nguyen, G. Frenking. Transition-Metal Complexes of Tetrylones $\left[(\mathrm{CO})_{5} \mathrm{~W}-\mathrm{E}\left(\mathrm{PPh}_{3}\right)_{2}\right]$ and Tetrylenes $\left[(\mathrm{CO}){ }_{5} \mathrm{~W}\right.$-NHE $] \quad(E=C-P b): A$ Theoretical Study, Chem. Eur. J., 18, 12733-12748 (2012).

15. T. A. N. Nguyen T. P. L. Huynh, T. X. P. Vo, T. H. Tran, D. S. Tran, T. H. Dang, T. Q. Duong. Structures, Energies, and Bonding Analysis of Monoaurated Complexes with N-Heterocyclic Carbene and Analogues, ASEAN J. Sc. Technol. Dev., 32, 1-15 (2015).

16. C. Boehme, G. Frenking. N-Heterocyclic Carbene, Silylene, and Germylene Complexes of $\mathrm{MCl}(\mathrm{M}=\mathrm{Cu}$, $\mathrm{Ag}, \mathrm{Au})$. A Theoretical Study, Organometallics, 17, 5801-5809 (1998).

17. C.-Y. Liao K. T. Chan, P. L. Chiu, C. Y. Chen, H. M. Lee. Structural variation in silver complexes with $\mathrm{N}$ heterocyclic carbene ligands bearing amido functionality, Inorg. Chim. Acta. 361, 2973-2978 (2008)

18. Y. Inagawa, S. Ishida, T. Iwamoto. Two-coordinate Dialkylsilylene-Coinage Metal Complexes, Chem. Lett., 43, 1665-1667 (2014).

19. N. Zhao J. Zhang, Y. Yang, H. Zhu, Y. Li, G. Fu. $\beta-$ Diketiminate Germylene-Supported Pentafluorophenylcopper(I) and -silver(I) Complexes $\left[\mathrm{LGe}(\mathrm{Me})\left(\mathrm{CuC}_{6} \mathrm{~F}_{5}\right) n\right]_{2} \quad(n=1, \quad 2)$, $\mathrm{LGe}\left[\mathrm{C}\left(\mathrm{SiMe}_{3}\right) \mathrm{N}_{2}\right] \mathrm{AgC} \mathrm{C}_{6} \mathrm{~F}_{5}, \quad$ and $\left\{\mathrm{LGe}\left[\mathrm{C}\left(\mathrm{SiMe}_{3}\right) \mathrm{N}_{2}\right]\left(\mathrm{AgC}_{6} \mathrm{~F}_{5}\right)_{2}\right\}_{2} \quad(\mathrm{~L}=\mathrm{HC}[\mathrm{C}(\mathrm{Me}) \mathrm{N}-$ 2,6-iPr $\left.\left.\mathrm{C}_{6} \mathrm{H}_{3}\right]_{2}\right): \quad$ Synthesis and Structural Characterization, Inorg. Chem., 51, 8710-8718 (2012)

20. P. B. Hitchcock M. F. Lappert, L. J. M. Pierssens Novel $\mathrm{Sn}^{I I}-\mathrm{Ag}^{I}$ Reactions from $\mathrm{Sn}\left[\mathrm{CH}\left(\mathrm{SiMe}_{3}\right)_{2}\right]_{2}$ and $A g X(X=N C S, C N, N C O$, or I $): S n^{I I}-A g^{I}$ or $S^{I V} X_{2}$ Complexes, Organometallics, 17, 2686-2688 (1998).

\section{Corresponding author: Nguyen Thi Ai Nhung}

Hue University of Sciences, Hue University

No. 77, Nguyen Hue, Hue City, Thua Thien Hue Province

E-mail: nguyenainhung.hueuni@gmail.com. 